\title{
EVALUATION OF BEHAVIOR OF CONNECTIONS THROUGH AUTOFLOWING SCREWS IN TREATED RADIATA PINE WOODEN PRESERVATIVES
}

\author{
GALO CÁRDENAS-TRIVIÑNO ${ }^{a^{*}}$, DIEGO ORTIZ-ÁVILA ${ }^{b}$, MARIO NUÑEZ-DECAP ${ }^{b}$, \\ AND ALEXANDER OPAZO-VEGA ${ }^{b}$

\begin{abstract}
${ }^{a}$ Department of Wood Engineering, School of Chemical Engineering, Faculty of Engineering, University of Bío-Bío, Concepción 4081112, Chile.
\end{abstract} \\ ${ }^{b}$ Department of Civil and Environmental Engineering, Faculty of Engineering, University of Bío-Bío, Concepción 4081112, Chile.
}

\begin{abstract}
Wood is a great material,it has a disadvantage of early deterioration due to external agents. For this reason, it is interesting to create a new wooden preservative. It was studied one based on a natural polymer (chitosan) and nanoparticles ( $\mathrm{Si}$ and Ti). Tests were carried out to characterize physical (density, moisture content, swelling and absorption) and mechanical properties (flexion, compression and hardness) of wood specimens with and without impregnation, and their joints with two types of self-drilling screws. Simple and lateral extraction test were carried out. Improvements in hardness and perpendicular compression are highlighted obtained, results indicate a stiffening of the fibers. This treatment achieves the material cross section hardening, coating it with components that help to delay the ignition and provide greater duration against external agents. From the extraction of screws, the impregnated wood allowed more rigid unions, with smaller displacements in comparison to the wood without treatment.
\end{abstract}

Keywords: Impregnation, Chitosan, Physical and mechanical properties, Wooden connectors.

\section{INTRODUCTION}

In order to reduce pollution generated by the construction industry, wood stands out due to its low contamination index and its excellent mechanical properties. Chile is a country with a great production of wood, in fact is inside the top 20 producers and traders of forest products worldwide. Nevertheless, only $17 \%$ of houses in the country are built based on wood as a structural material and would impact positively to increase those numbers and enhance this material in the national construction industry.

From the engineering and architecture point of view, wood has great qualities, such as its strength and durability, in addition to being lightweight, easy to transport and manipulate [1]. It behaves well during seismic movements, since these need heavier objects to unleash its destructive power, which the wood does not possess. The wood is increasing in their use at the national level, but it is still low compared to their production, because of this it is necessary to strengthen it [2-4].

The wood is a structural material with large mechanical and physical properties, but its good performance is limited to external agents, UV light or rain for extended periods will affect it negatively weakening it, making it loose their properties. For this reason, a series of treatments have been created to solve these problems. These treatments must be applied before building, as it is the case of impregnation, or later, as paints or varnishes [1].

But in the construction, this material is not individually used. It is worked by connectors, even wood-wood joined pieces or wood-other type of material. The connectors must be able to hold large loads, to avoid a potential failure and provide security. There are metal ones such as nails or screws connectors, plates, which can be embedded in the wood or covering it, and there are also glued connections [5].

This article covers a researched problem, which is the behavior of the wood treated in conjunction with metal type plug connectors. There is research on the mechanical properties of wood treated with a preservative, which evaluates whether these improve or simply does not affect them. There are also research on this type of connectors, but wood without treatment, providing a basis for the preparation of trials. Physical and mechanical properties that can be evaluated in the wood are varied, so it seeks to know what are the most relevant to study. Rodríguez and Vergara 2008 studied mechanical and physical properties of the wood of pinus canariensis grown in the region of Maule. The methodology used could be obtained from this study and that are more closely linked to the research [6]. Many investigations have determined that the mechanical properties do not have significant differences in the wood treated with CCA, only the hardness and the cutting parallel to the fibers obtained improvements [7-9]. These data were obtained through the ASTM-D 1761 [10] (American Society for Testing and Materials).

Luna et al. 2014, conducted a study of extraction of nail and screw in 4 different species of pine [11]. Screws had dimensions of 4 x $50 \mathrm{~mm}$ steel Bugle head flat and slot Phillips, which were cleaned before use. Trials were based on the standard ASTM-D 1761 [10] and the results gave as higher-value extraction pinus douglasiana wood with $3087.882 \mathrm{~N}$. From the texts quoted above can rescue the methodology that was used to carry out trials, both to characterize the material as the connection with screw. In addition, a study where a treatment is applied to improve the properties of wood, similar to the studies in this research. These investigations show that the preservatives can improves the properties of the wood. In addition, you can compare if the union also had improvements.

As well mention before, wood is a material that loses its properties to come into contact with different external agents, such as fungi, insects, or the same climate. Therefore, it becomes necessary to add components that improve these qualities that is the case of the preservatives, which provide longer life to wood. A preservative which contained pure materials, that will be described below was developed in this research.

The Rosin is a natural resin, which can be extracted both live trees, dead trees and has a yellowish color. It has different uses, including two in particular, which are used in adhesives and as a biocide. Within the mix stands more masking feature that has, since he is responsible for all the components to remain attached to the wood to the permeate.

Lignin is a biopolymer present in plants, which possesses properties fungicides, as well as being used in the production of adhesives. Silicon dioxide provides resistance to the weathering due to sunlight and moisture, which severely affect the wood.

Titanium dioxide is added in the form of nanoparticles to the mix, but not be soluble, suspended is in this. It aims to improve the resistance to degradation by fungi or by climatic factors, as well as improving the physical and mechanical properties. These last two are still being investigated by scientists, to specifically know that property improves.

The physical properties such as density, moisture content, shrinkage and swelling are all those characteristics of the wood to characterize it. Moisture content states the percentage of water in the wood compared to the percentage of the dry mass of wood. In other words, is the amount of water retained in the fibers of the wood, which if you exceed the $20 \%$ is considered wet.

Density is the amount of mass of a body in a given volume or space, which may vary among wood species or within the same species. Pinus Radiata wood is considered a little dense material, hovering around the $450 \mathrm{~kg} / \mathrm{m}^{3}[12]$ as a mean value. This value it is considered a wood as a light weight material compared to the $7850 \mathrm{~kg} / \mathrm{m}^{3}$ that has steel determines only is valid in the elastic area [13]. Break voltage corresponds to the maximum load per unit area when it applies a compressive load on the test specimen. The load can be applied both to the direction parallel to the fibers of the wood to the perpendicular.

The following are some of the mechanical properties of structural wood, which are used in this study. Flexibility is the resistance that has wood to loads applied perpendicular to the fibers, bowing and generating efforts of traction and compression at the same time. It evaluates according to the module of elasticity 
(MOE) or modulus of rupture (MOR), characterizing the rigidity and strength of wood. The density and angle holding the wood fiber directly affect these parameters, and can improve it or decrease them.

The MOR as well as the MOE are parameters that allows to know the strength of a material only that in this case is the maximum strength, until the material fails. This parameter does not correspond to a real tension, since the formula with which drilling guide. The Drywall screw has the same head and slot above screw but differ in their thread, since it is thicker. Both are made with a tempered steel, only covering the first screw is zinc and of the second screw is phosphatized in oil.

Swelling is the ability of wood to increase its size, length, width, or thickness, to come into prolonged contact with water. Due to the anisotropy of the internal structure of the wood, this process depends on the direction in which we analyze. The mechanical properties are those that describe the behavior of the material to different external loads, such as bending, compression, traction, among others. This characteristic of wood can vary depending on moisture content which possess or the density of the same, as well as the direction in which the charge applies. This is due to the anisotropy of wood by which a distinction according to the direction of the fiber, which can be parallel or perpendicular to the growth of the tree should be. Two types of metallic connectors type screws for treated and untreated lumber were used, which are the drywall screw and turbo screw.

The goal of the work was to evaluate the MOE, MOR and other physicmechanic parameters of pine wood specimen to evaluate the performance of this new biocompatible preservatives.

\section{EXPERIMENTAL}

\subsection{Samples}

Specimens of radiata pine wood with grade $\mathrm{G} 1$ and better, with dimensions of $41 \times 91 \times 350 \mathrm{~mm} 3$, flawless visual, dry and brushed. The specimens of wood pattern and wood impregnated with dimensions requiring each test according to the standards. In addition, needed a wooden board OSB structural, possessing a thickness of $11.1 \mathrm{~mm}$ and two types of screws, one is the drywall CRS number 6 x $115.875 \mathrm{~mm}$ steel and the other is the turbo screw number 6 x $112.7 \mathrm{~mm}$, is made of tempered steel (Figure 1).

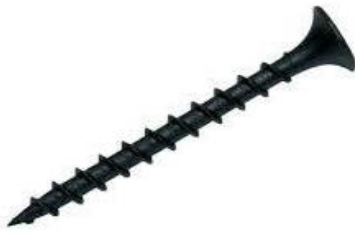

a)

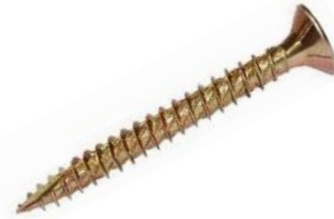

b)
Figure 1. a) Drywall screw, b) Turbo screw

Two types of screws are discussed in this study because it not only wanted to compare treated and untreated wood, but also sought to do with screw behaved better. The Drywall screw for chipboard or cardboard plaster plates and the screw Turbo special for hardwoods was chosen. The difference between these is that the first thread is more thick and larger, and the second has cutting nerves at the bottom of the thread and a milled end. Therefore, it seems relevant as this type of thread interacts with the effect of the impregnation.

\subsection{Wood Preservatives}

The following raw materials, with their respective dosages, were used for the elaboration of the impregnation:

Table 1: Composition of impregnating biodegradable liquid.

\begin{tabular}{|c|c|}
\hline Component & Concentration $(\mathrm{g} / \mathbf{L})$ \\
\hline Lignin & $10-20$ \\
\hline Nanosodium Silicate & $8-12$ \\
\hline Nanotitanium Dioxide & $8-12$ \\
\hline Esterified Rosin & $15-20$ \\
\hline
\end{tabular}

Five liters of mixture were manufactured. The rosin esterified was diluted in $2.5 \mathrm{~L}$ of ethanol and $2.5 \mathrm{~L}$ of distilled water stirred by a magnetic stirrer. Subsequently, the other compounds were added, while stirring, for 30 minutes at $400 \mathrm{rpm}$, to achieve a homogeneous mixture.

To achieve better penetration of inorganic particles (sodium silicate and titanium dioxide), they needed to be significantly reduced. This was done with a homogenizer, Ultraturrax T-25 at $10000 \mathrm{rpm}$, for one hour. Once this process was finished, the mixture was further diluted in $15 \mathrm{~L}$ of distilled water, obtaining $20 \mathrm{~L}$ of impregnant.

\subsection{Impregnation method}

To get better penetration in the wood, samples were cut with the dimensions described in each trial. This is given to the specimens to reduce its dimensions, in which the preservative should penetrate into smaller cross sections. The impregnation method used was that of vacuum-pressure-vacuum, which consists of introducing the pieces of wood inside a cylindrical tank. At the same time the preservative is inserted into a storage tank of similar characteristics that connects through the hoses with his counterpart. Once placed the pieces inside the autoclave is applied a $0.6 \mathrm{MPa}$ vacuum for 30 minutes, where the applied pressure is given by the device used.

Without stopping the void initial, proceed to enter the preservative at room temperature, and a pressure of 0.6 MPa is applied for one hour. After this time, the preservative back to the storage tank is pumped, and a vacuum end is applied in the cylinder to remove the surplus of this. Since the parts are of dimensions preventing cracks in small faces, instead specimens are left a day at room temperature. To complete the process the specimens were left to dry in an oven at $45^{\circ} \mathrm{C}$ for 3 days.

\subsection{SEM (scanning electron microscopy)}

This test pattern shows internal impregnated specimen and wood structure without soak, to see the penetration of the preservative. In addition to help understand the possible effects generated in these fibers. Analyses that were allowed to visualize the fibers of the wood treatment and without it, as well as obtaining a percentage of some components attached to the material. The trial was conducted by 1300 micrometers $(\mu \mathrm{m})$ specimens.

The specimens were obtained from cutting pieces of wood with and without impregnation, then they assayed in the longitudinal and transverse direction fiber, for later analysis. In addition, there were quantities, in percentage, for each component of the impregnation, for the same above directions.

\subsection{TGA (thermogravimetric analyses)}

A thermogravimetric analysis (TGA) to pieces of wood were tested to obtain thermal properties of the samples. This test is performed on a TA Model Q50 in an inert atmosphere (nitrogen) and a heating rate of $10{ }^{\circ} \mathrm{C} / \mathrm{min}$.

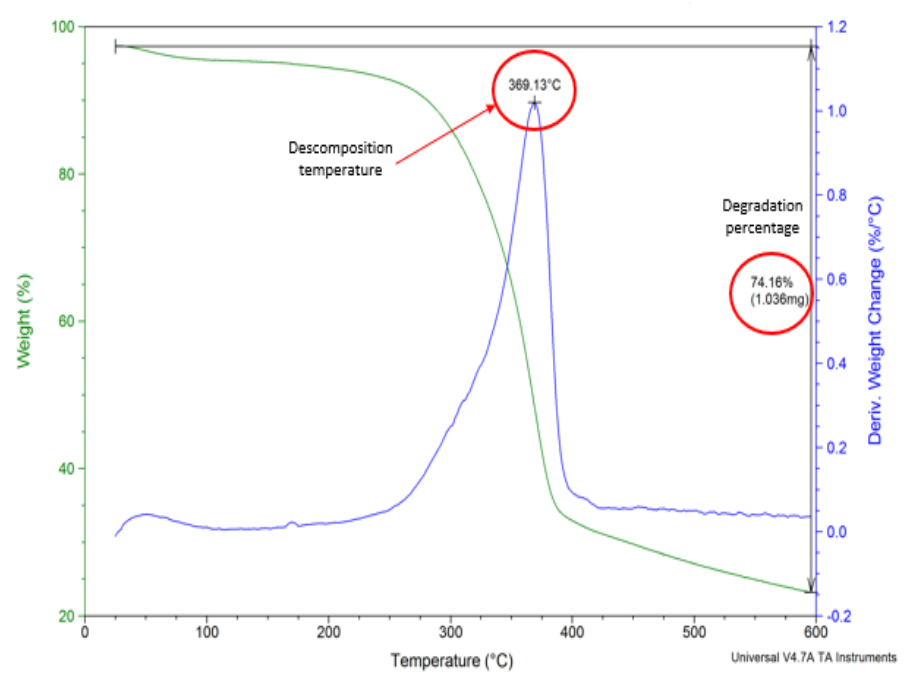

Figure 2. TGA of impregnated wood. 


\subsection{Density}

The calculation of the density was obtained through the equation.

$\rho=\frac{m}{v}$

Where $\rho=$ the density, expressed in $\mathrm{kg} / \mathrm{m}^{3}$

$\mathrm{m}=$ the mass, expressed in $\mathrm{kg}$

$\mathrm{v}=$ the volume, expressed in $\mathrm{m}^{3}$

Where the mass was obtained weighing on each specimen in an electronic scale, while the volume was obtained by multiplying each of its dimensions (width, thickness and length) measured with a digital meter foot. This parameter was calculated for all specimens of each of the tests [14].

\subsection{Moisture content}

Wood humidity is the ratio of the amount of water that it has, in comparison to its mass, and should be appropriate to the environment in which this material is used. The content of humidity of wood parts was obtained through a hygrometer, where a single face of the specimen is penetrated. This method is applicable when the moisture content of the wood is between the values of $7 \%$ and $28 \%$ [15]. The method is to penetrate the test tubes with needles or electrodes on one of its sides, perpendicularly, and making the electrodes enter fully. The surface should not have visible defects, surface moisture nor dirt, since they may alter the measurements, throwing no reliable data. The contents of moisture, both of wood pattern and impregnated wood, were measured in all specimens for each test. Flex testing and lateral extraction specimens, measurements were made at each end of this face and the Centre. In other trials were not performed the measurement from the Center, because of the length of the pieces of wood. After obtaining all the measurements, these were averaged, obtaining a single percentage of moisture that characterized it.

\subsection{Absorption and swelling test}

Trial of absorption and swelling were made with 5 specimens of $25 \times 25 \times 100$ $\mathrm{mm}^{3}$, both wood impregnated as pattern, for wood which will get the absorption and swelling of each material [16]. Three measurements for each side, which were averaged, resulting in the dimensions of width, thickness and height. In addition, it was recorded the weight of each piece. With these data the density of the specimens is calculated, and later its moisture content were measured. Specimens were spaced with each other and covered with a mesh, thus attaining that wood could expand in any of its dimensions. They entered into a container and water, poured them in such a way that the specimens remain completely submerged during 24 hours. In addition to this, it was necessary to put a weight on the mesh, because wood tends to float, and would affect the results of the trial. After that time, the specimens were removed from the vessel and leaves to dry for 2 hours, where again their three dimensions and weight were measured. Thus, the percentage of volumetric expansion and absorption of every piece of wood was calculated, as shown in equations 2 and 3.

$G t=\frac{V 2-V 1}{V 1} \times 100$

Where $\mathrm{Gt}=$ Swelling, expressed as a percentage $(\%)$.

$\mathrm{V} 1=$ volume of the specimen before the dive, expressed in $\mathrm{m}^{3}$.

$\mathrm{V} 2=$ Volume of the specimen after the dive, expressed in $\mathrm{m}^{3}$.

$A=\frac{m 2-m 1}{m 1} \times 100$

Where $\mathrm{A}=$ absorption, expressed in percentage (\%).

$\mathrm{m} 1$ = Mass of the test piece before the dive, expressed in $\mathrm{kg}$.

$\mathrm{m} 2=$ Mass of the specimen after the dive, expressed in $\mathrm{kg}$.

\subsection{Flexion test}

The specimens were manufactured with dimensions of $25 \times 25 \times 410 \mathrm{~mm}^{3}$, with a number of seven pieces for wood pattern and impregnated wood. The measurements were performed with the universal model 4468 INSTRON testing machine, and following the steps laid down in the secondary method of [13]. Load head stood right in the middle of the specimen on the tangential face of this for the subsequent application of load. To start the test, the machine required to enter the thickness of each test piece, which is measured with a digital meter foot. The speed of the test was $1.625 \mathrm{~mm} / \mathrm{min}$.

\subsection{Parallel compression test}

In this trial 10 specimens of $25 \times 25 \times 100 \mathrm{~mm}^{3}$ for each type of wood, assayed according to the [17]. The test speed was $0.75 \mathrm{~mm} / \mathrm{min}$, and stopped when the compression decreased up to $20 \%$ of the maximum load. With this method pattern, was obtained the modulus of elasticity and the breaking strain, both for wood and impregnated wood.

\subsection{Perpendicular compression test}

For this type of test, 5 wood specimens of $41 \times 41 \times 150 \mathrm{~mm}^{3}$, as shown in the [18]. Rate applied of $0.375 \mathrm{~mm} / \mathrm{min}$, taking readings of load and displacement of deformation point in which reached $2.5 \mathrm{~mm}$. As a result the breaking strain of the material is in the perpendicular direction of the fibers.

\subsection{Hardness test}

This method consists in penetrating the faces of the specimens with an $11.3 \mathrm{~mm}$ diameter steel sphere, up to the half of the specimen [19]. Samples are $41 \times 41 \times 150 \mathrm{~mm}^{3}$ and placed in horizontally INSTRON machine, where the application of the compression load is perpendicular to the direction of the fiber. Uploaded 4 longitudinal faces of each specimen at a speed of $7.5 \mathrm{~mm} / \mathrm{min}$, by averaging values obtained, achieving a single value of load for each test piece.

\subsection{Lateral extraction test}

In this method was analyzed the behavior of each specimen to be united with a structural or plate OSB, via two connectors type screws. 20 test pieces of $41 \times 41 \times 300 \mathrm{~mm}^{3}$ made by wood type, and for each test piece manufactured pieces of $50 \times 300 \mathrm{~mm}^{2}$ of structural OSB ASTM-D 1761[10]. 20 specimens, a half using black screws drywall, and the other half one screw Gold turbo screw, as a method of union between the piece of wood and the OSB Board. A drilling was carried out guide of three millimeters in diameter, with a depth of $20 \mathrm{~mm}$, to the half of the width of one longitudinal side.

Added a clock comparator that is measuring the displacement of the plate on the piece of wood at the time of pulling the specimen. The test speed was $3.175 \mathrm{~mm} / \mathrm{min}$, and this stopped when the specimen fails, either on the piece of wood, screw or plate of OSB. Trial was obtained the maximum load and its associated displacement, in addition the rigidity of the screws was calculated through equation 4 . Values 0.4 and 0.1 that multiply the maximum load ensure calculation of stiffness in the elastic range of the material.

$$
K=\frac{F_{\max 0,4}-F_{\max 0,1}}{D_{F \max 0,4}-D_{F \max 0,1}}
$$

Where: $\mathrm{K}=$ Rigidity of the material, expressed in $\mathrm{kN} / \mathrm{m}$.

Fmax $0.4=$ Maximum load screw multiplied by 0.4 expressed in $\mathrm{kN}$.

Fmax $0.1=$ Maximum load screw multiplied by 0.1 expressed in $\mathrm{kN}$.

DFmax $0.4=$ Displacement of screw associated with Fmax 0.4 expressed in $\mathrm{m}$.

DFmax $0.1=$ Displacement of screw associated with Fmax 0.1 expressed in m.

\subsection{Simple extraction test}

To characterize the adherence of the two screws connector type, wood pattern and impregnated wood, manufactured 20 specimens of $41 \times 41 \times 150 \mathrm{~mm}^{3}$ for each. Each specimen contained six screws, two on each longitudinal side (radial and tangential) and two on the transverse faces, as described in standard [10] (Figure 3). Before placing the screws in the specimens, was carried out a drilling guide in the direction of these, with a diameter of $3 \mathrm{~mm}$ and a depth of $26 \mathrm{~mm}$. 


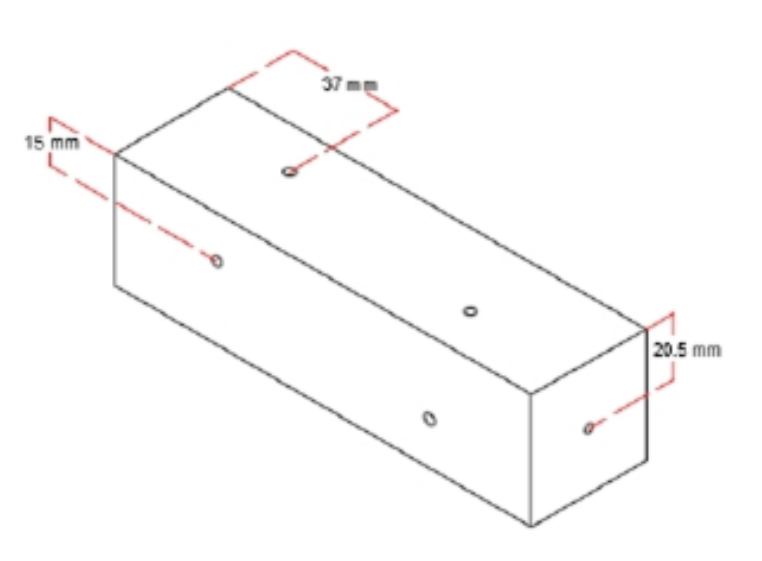

Figure 3. Scheme of the spacing of the perforations Guide for trials of simple removal of screws.

To place the test pieces in the machine INSTRON used a wedge, which held the head of the screw, and a steel plate with a hole in the Middle, which held the piece of wood. The plate had a thickness of $5 \mathrm{~mm}$ to be sufficiently rigid to guard against deformation in the trial, also covered the entire surface of the face which was extracted from him the screw, avoiding any slip of wood. The speed of extraction is $3.175 \mathrm{~mm} / \mathrm{min}$, getting traction resistances and the displacement of the screw for the burden. Averaged resistances of the four screws in the longitudinal faces and the two screws on the transverse faces of each specimen, resulting in a longitudinal load and a transverse load.

\section{RESULTS AND DISCUSSION}

\subsection{Characterization of Silicon and Titanate nanoparticles}

The following figure 4a shows the silicon nanoparticles with a mixture of flat, spherical and ellipsoidal shapes.

a)

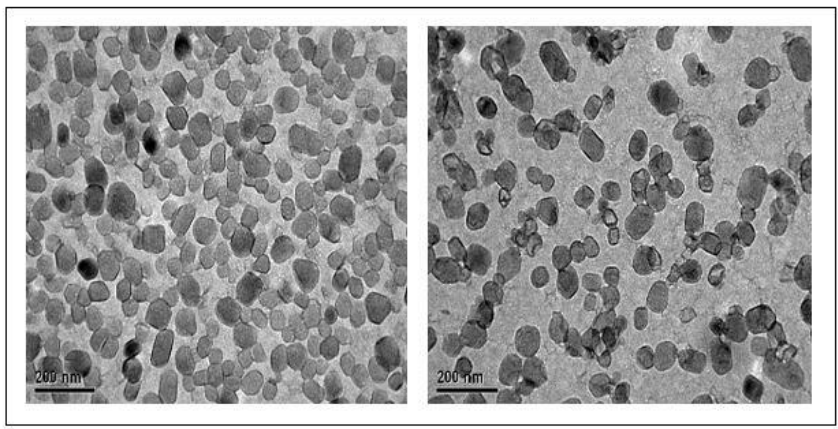

b)

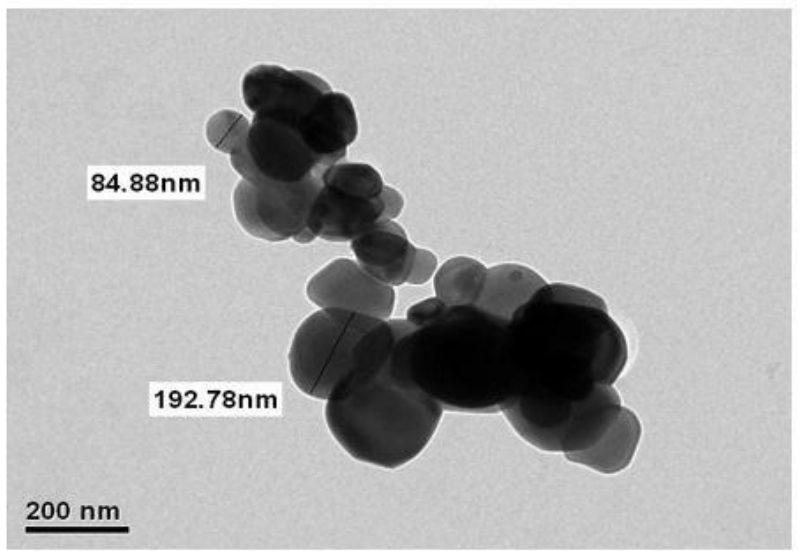

Figure 4. a) Silicon dioxide nanoparticles with average particle size of 74.05 $\pm 11.12 \mathrm{~nm}, \mathrm{~b}$ ) Titanium dioxide nanoparticles with portions of average particle size of $85 \mathrm{~nm}$ and other areas with average $190 \mathrm{~nm}$.

\subsection{Characterization of materia}

At this point show the data of the physical characteristics measured in the test of swelling. Thermal characterization of each material will be delivered through a thermogravimetric, in addition to the morphology of each material analysis. The delivered batch of wood density is $434.25 \mathrm{~kg} / \mathrm{m}^{3}$, while the moisture content is $10.13 \%$.

Table 2: Summary of swelling test

\begin{tabular}{|l|c|c|c|}
\hline \multirow{2}{*}{ Parameters } & \multirow{2}{*}{$\begin{array}{c}\text { Number of } \\
\text { Samples }\end{array}$} & $\begin{array}{c}\text { Impregnated } \\
\text { Wood }\end{array}$ & $\begin{array}{c}\text { Standard } \\
\text { Wood }\end{array}$ \\
\cline { 3 - 4 } & Mean & Mean \\
\hline Density $\left(\mathbf{k g} / \mathbf{m}^{\mathbf{3}}\right)$ & 5 & 359.20 & 440.83 \\
\hline Moisture content (\%) & 5 & 3.50 & 10.32 \\
\hline Swelling (\%) & 5 & 6.24 & 7.68 \\
\hline Absorption (\%) & 5 & 64.35 & 38.25 \\
\hline
\end{tabular}

The results of table 2 clearly show a difference for each of the parameters that are presented in the two figures. Impregnated wood was in a drying oven for three days, which is reflected in lower moisture that it possesses regarding the pattern, so that it absorbed more water. Despite this same was minor swelling in the impregnated wood, which is a benefit in comparison to wood pattern.

Table 3: Summary of thermogravimetric test

\begin{tabular}{|l|l|l|l|}
\hline \multirow{2}{*}{ Test } & Type of wood & $\begin{array}{l}\text { Decomposition } \\
\text { temperature }\left({ }^{\circ} \mathbf{C}\right)\end{array}$ & $\begin{array}{l}\text { Residual } \\
\text { mass }(\%)\end{array}$ \\
\hline \multirow{2}{*}{ TGA } & Impregnated & 369.13 & 25.84 \\
\cline { 2 - 4 } & Standard & 385.27 & 17.93 \\
\hline
\end{tabular}

In the analysis thermogravimetric seen as differing values of the decomposition temperature and the percentage of waste. It is clear that impregnated wood was degraded to a lesser extent, shown with the percentage of residues, which was higher due to the nanocomposites in it. The temperature of decomposition was similar between both materials, without observing a minor reduction from the impregnated wood.

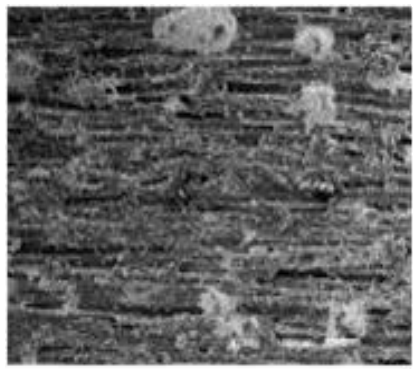

a)

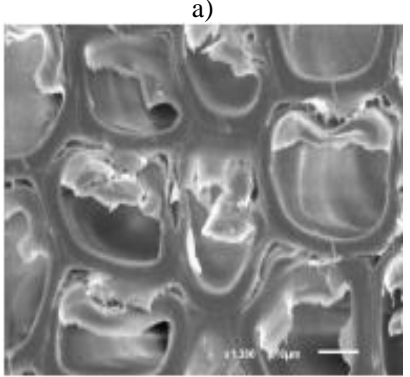

c)

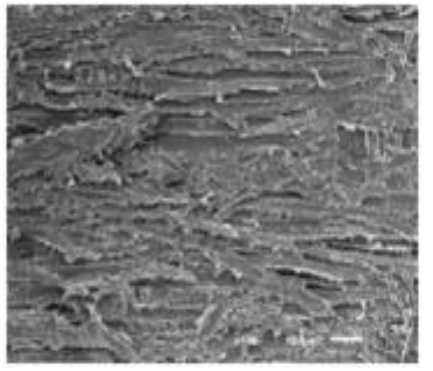

b)

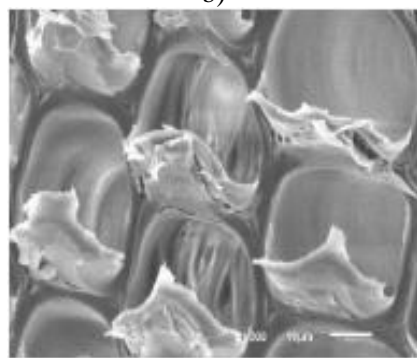

d)
Figure 5. a) Slitting of wood impregnated with increase to $100 \mu \mathrm{m}, \mathrm{b}$ ) Longitudinal cutting of wood pattern with increasing to $100 \mu \mathrm{m}, \mathrm{c})$ cross cutting in wood impregnated with increased to $1300 \mu \mathrm{m}, \mathrm{d}$ ) crosscutting wood pattern with increase to $1300 \mu \mathrm{m}$.

In Figure 5, you can see a clear difference in the two directions of cuts of wood impregnated and pattern parts. When ripping or cross-cutting, untreated wood fibers were most damaged, showing greater stiffness in treated lumber. In addition, you can see as the preservatives joined fibers, in the form of small white spots on them. 


\subsection{Mechanic Properties}

For tests that characterize the mechanical properties of each material, was a table summary with the average obtained in each.

Table 4: Mechanical properties for wood types

\begin{tabular}{|c|c|c|c|c|}
\hline \multirow[t]{2}{*}{ Test } & \multirow{2}{*}{$\begin{array}{c}\text { Number of } \\
\text { Samples }\end{array}$} & \multirow[t]{2}{*}{ Parameters } & \begin{tabular}{|c|}
$\begin{array}{c}\text { Impregnated } \\
\text { Wood }\end{array}$ \\
\end{tabular} & $\begin{array}{c}\text { Standard } \\
\text { Wood }\end{array}$ \\
\hline & & & Mean & Mean \\
\hline \multirow{2}{*}{ Flexural } & \multirow{2}{*}{7} & $\begin{array}{c}\text { Young } \\
\text { Modulus (MPa) }\end{array}$ & 6733.43 & 6961.71 \\
\hline & & $\begin{array}{c}\text { Flexural } \\
\text { Modulus (MPa) }\end{array}$ & 70.47 & 61.58 \\
\hline \multirow{2}{*}{$\begin{array}{l}\text { Parallel } \\
\text { compression }\end{array}$} & \multirow{2}{*}{10} & $\begin{array}{c}\text { Young } \\
\text { Modulus (MPa) }\end{array}$ & 1795.80 & 2214.30 \\
\hline & & $\begin{array}{c}\text { Ultimate } \\
\text { Strength (MPa) }\end{array}$ & 39.09 & 35.82 \\
\hline $\begin{array}{l}\text { Perpendicular } \\
\text { compression }\end{array}$ & 5 & $\begin{array}{c}\text { Ultimate } \\
\text { Strength (MPa) }\end{array}$ & 10.65 & 8.67 \\
\hline Hardness & 10 & $\begin{array}{c}\text { Maximum load } \\
(\mathrm{kN})\end{array}$ & 2.98 & 2.56 \\
\hline
\end{tabular}

Table 4 shows that all the parameters relating to the maximum load and breaking strain showed improvements in wood impregnated with respect to the pattern. In contrast to the modulus of elasticity was not achieved an increase, basically were not affected with the treatment for the wood. Of these last seen they resemble the modulus of elasticity of radiata pine wood degree structural G1 and best [12]. This wood is visual, when parts do not possess any kind of defect, and the specimens possessed those characteristics.

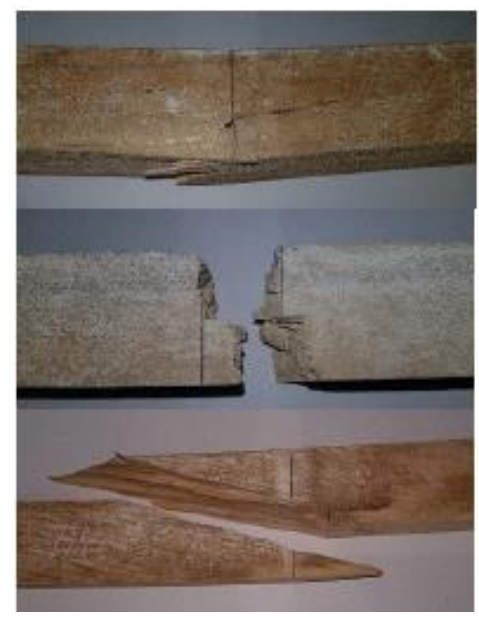

a)

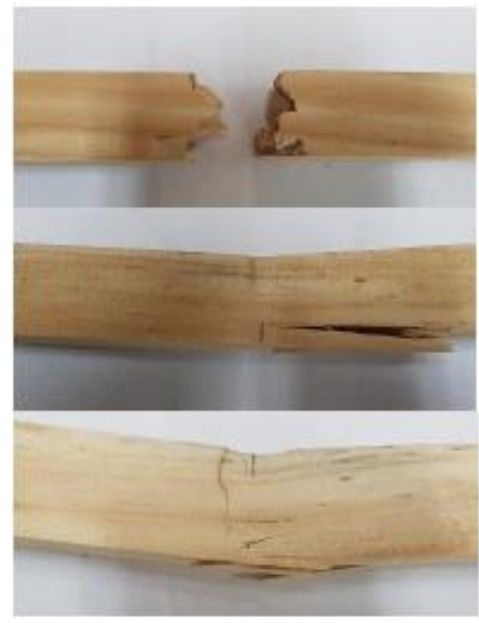

c)

Figure 6. a) Types of failure in the trial to bending of impregnated wood, b) Types of failure in the trial to bending of wood pattern.
Figure 6, failure modes between treated and untreated were similar, only that the first specimens tended to be cut completely. Failure of the specimens of wood pattern dominance break in the area stressed of the material, i.e. the face contrary to the application of force.

\subsection{Linkages properties}

Of the tests, were certain values that were summarized in table 5, for each type of wood and each type of screw. For the lateral extraction test were recorded values of maximum load with their respective movement and stiffness of joints. Simple extraction test only recorded maximum load applied perpendicular to the fiber and parallel to the fiber.

Table 5: Properties summary of each kind of wood joints.

\begin{tabular}{|c|c|c|c|c|}
\hline \multirow[t]{2}{*}{ Test } & \multirow{2}{*}{$\begin{array}{c}\text { Number of } \\
\text { samples }\end{array}$} & \multirow[t]{2}{*}{ Properties } & \begin{tabular}{|c} 
Impregnated \\
Wood
\end{tabular} & \begin{tabular}{|c} 
Standard \\
Wood
\end{tabular} \\
\hline & & & Mean & Mean \\
\hline \multirow{6}{*}{$\begin{array}{l}\text { Lateral } \\
\text { Extraction }\end{array}$} & \multirow{6}{*}{10} & Max. Load TD (kN) & 1.85 & 1.74 \\
\hline & & Max. Load TTS $(\mathrm{kN})$ & 1.29 & 1.42 \\
\hline & & Displacement TD (mm) & 10.48 & 15.62 \\
\hline & & Displacement TTS (mm) & 8.53 & 11.93 \\
\hline & & Stiffness TD (kN) & 305.38 & 214.70 \\
\hline & & Stiffness TTS $(\mathrm{kN})$ & 29.25 & 236.10 \\
\hline \multirow{2}{*}{$\begin{array}{l}\text { Simple P. } \\
\text { Extraction }\end{array}$} & \multirow{2}{*}{10} & Max. Load TD (kN) & 2.24 & 2.58 \\
\hline & & Max. Load TTS (kN) & 2.05 & 2.00 \\
\hline \multirow{2}{*}{$\begin{array}{l}\text { Simple P.* } \\
\text { Extraction }\end{array}$} & \multirow{2}{*}{10} & Max. Load TD (kN) & 2.03 & 1.93 \\
\hline & & Max. Load TTS (kN) & 1.54 & 1.40 \\
\hline
\end{tabular}

Table 5 you can see that improvements in the test side extraction for impregnated wood were obtained, less the maximum screw load turbo screw. You can see that movements were lower and that-unions have greater rigidity compared with the wood pattern.

In the trial of simple extraction, to the direction perpendicular to the fiber, improvements in wood impregnated with respect to pattern was not achieved, the maximum load of the Turbo screw was of the same order. In the case of screw Drywall is a decrease in the maximum load, which is must be the difference in densities between the specimens. In the parallel direction is an improvement from the impregnated wood, for each screw, showing greater rigidity.

Then the analysis of the data tabulated above will be presented, either for the characterization of materials, mechanical properties and owned by the unions. In essence, the analyses were based on a comparison between the wood pattern and wood impregnated, for each type of method. We sought the possibility that there were significant differences, and that if so, examine whether the impregnated wood behaved better than wood pattern.

To observe these differences, began contrasting the mean, standard deviation and coefficient of variation for each type of wood by trial. After an analysis $t$ of two samples, or an analysis ANOVA, for data that possessed a normal distribution. The p-value indicates whether or not significant differences, if it is less than 0.05 means that if, if not discarded it.

The density of the specimens in general, both treated and untreated, does not have a significant difference, obtaining a value equal to $0.526 \mathrm{p}$.

Table 6: Analysis of two samples swelling test of two samples.

\begin{tabular}{|l|c|c|c|}
\hline \multirow{2}{*}{ Properties } & Impregnated Wood & Standard Wood & \multirow{2}{*}{ p Parameter } \\
\cline { 2 - 4 } & Mean & Mean & \\
\hline Density $\left(\mathbf{k g} / \mathbf{m}^{\mathbf{3}}\right)$ & 359.20 & 440.83 & 0.012 \\
\hline Moisture (\%) & 3.50 & 10.32 & - \\
\hline Swelling (\%) & 6.24 & 7.68 & 0.105 \\
\hline Absorption (\%) & 64.35 & 38.25 & 0.006 \\
\hline
\end{tabular}

Table 6 shows that only in the case of the absorption a significant difference arose, but because that impregnated wood specimens had lower moisture content. Since this is not possible to indicate which of the two types of wood behaved 
better, for this type of test. The density of the specimens is similar, since they come from a same wood, the decrease in density of the impregnated wood is due to the low moisture content. The data obtained on the mechanical properties of wood in each trial, summarized in the following table:

Table 7: Two samples t analysis results, mechanical properties of wood pattern and impregnated one.

\begin{tabular}{|c|c|c|c|c|c|c|c|c|}
\hline \multirow[b]{2}{*}{ Test } & \multirow[b]{2}{*}{ Propertie } & \multicolumn{3}{|c|}{ Impregnated Wood } & \multicolumn{3}{|c|}{ Standard Wood } & \multirow[b]{2}{*}{$\begin{array}{c}\mathbf{p} \\
\text { Parameter }\end{array}$} \\
\hline & & Mean & Standard Desv. & $\begin{array}{c}\text { Var. } \\
\text { Coefficient }\end{array}$ & Media & Standard Desv. & $\begin{array}{c}\text { Var. Coefficient } \\
(\%)\end{array}$ & \\
\hline \multirow{2}{*}{ Flexural } & Young modulus (MPa) & 6733.34 & 1433.56 & 21.29 & 6961.71 & 1587.93 & 22.81 & 0.609 \\
\hline & Flexural modulus (MPa) & 70.47 & 12.80 & 18.17 & 61.58 & 17.11 & 11.93 & 0.071 \\
\hline \multirow{2}{*}{ Parallel Compression } & Young modulus (MPa) & 1795.80 & 319.42 & 17.79 & 2214.30 & 401.96 & 18.15 & 0.990 \\
\hline & Ultimate Strength (MPa) & 39.09 & 6.18 & 15.82 & 35.82 & 5.81 & 16.21 & 0.133 \\
\hline Perpendicular Compression & Ultimate Strength (MPa) & 10.65 & 2.01 & 18.83 & 8.67 & 1.04 & 11.99 & 0.049 \\
\hline Hardness & Max. Load (kN) & 2.98 & 0.61 & 20.30 & 2.56 & 0.43 & 16.68 & 0.044 \\
\hline
\end{tabular}

In the hardness and perpendicular compression testing, is clearly an improvement by the radiata pine wood impregnated. In the other two trials not shown this behavior, but if you can see a trend towards improvement in the MOR of the bending test. The coefficients of variation are in the order of $20 \%$ or less, which is an acceptable range in the dispersion of the data. Parallel compression test, there is a significant difference in the density of the specimens, which can affect the analysis of this trial. By which divided the MOE and the breaking strain by the density, avoiding the influence of the latter in the results. To do this, was verified that impregnated wood behaved better on the break, with a p-value voltage parameter $<0.01$

The data obtained on the characterization of connectors in each trial, summarized in the following table:

Table 8: Results and analysis of the trials of properties of joints of wood pattern and impregnated.

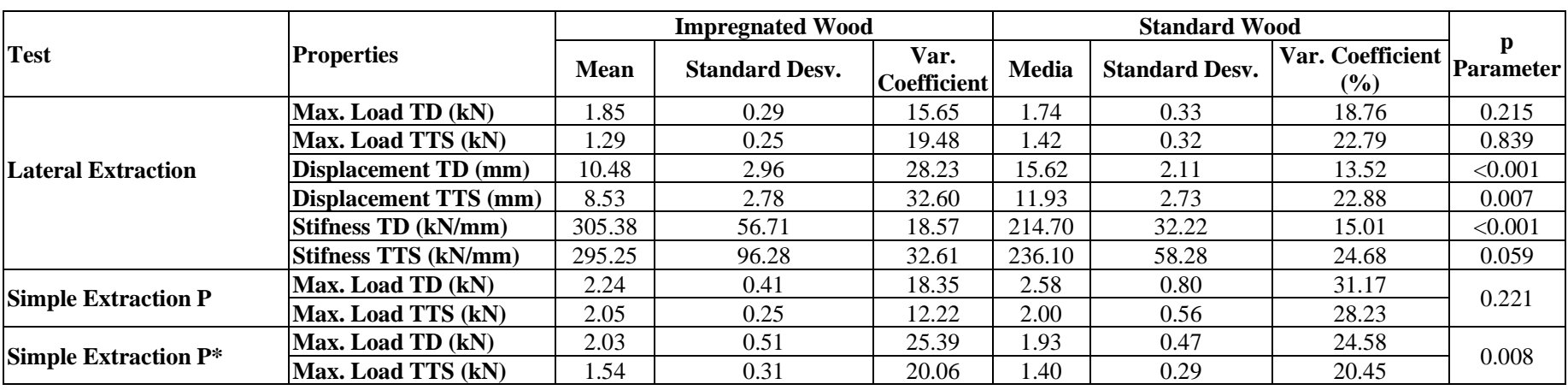

Lateral extraction test analysis at of two samples, comparing the types of wood for each screw, for both load, displacement and rigidity. There was a significant difference in the case of loads, but yes to the displacement and rigidity, where impregnated wood behaved better for every screw. With these parameters clearly seen the stiffening of the impregnation in wood, with which you can get longerlasting unions. In the trial of simple extraction was performed an ANOVA analysis, which compared the two types of wood with two types of screws. The existence of a difference between the averages, is looked for according to the direction in which it was the screw, either perpendicular or parallel.

The first significant difference between any screw or wood, but in the second were not recorded if differences were found. The maximum load of the screws in the impregnated wood was higher, but this difference is not significant with respect to the wood pattern. The difference is given between screws, since you clearly see how both woods Drywall screw behaved better than the Turbo wood Screw pattern. You can see that the coefficient of variation, for certain properties to evaluate, exceeds $20 \%$ resulting in data of high variability.

\section{DISCUSSION}

The impregnated wood exhibit a lower hydrophilicity compared with pattern wood, most probably due to the humidity around $10 \%$ of the composites and to the presence of nanoparticles smaller than $100 \mathrm{~nm}$.

The thermal analyses showed a better thermal properties due to the presence of nanoparticles, but the residual mass increases, which is consistent with other doped polymers already reported [20]. The impregnated wood under the SEM micrograph exhibit a more aligned fibers and small white spots that helps to give more resistance.

In the flexural test, the Young Modulus of impregnated wood shows a lower value $6733 \mathrm{MPa}$ against $6962 \mathrm{MPa}$ of standard wood, but in the flexural modulus the impregnated wood exhibit $70.5 \mathrm{MPa}$ compared with 61.6 of standard wood. On the other hand, in the parallel compress the Young modulus shows 1795.8 for impregnates wood and 2214.3 MPa while the ultimate strength exhibit 39.1 for impregnated wood compared with $35.8 \mathrm{Mpa}$ of standard wood. Meanwhile, in the perpendicular compress, the ultimate strength shows 10.6 for impregnated wood against 8.7 of standard wood. The hardness is also higher for impregnated wood 2.98 versus $2.56 \mathrm{kN}$. The radiate pine wood impregnated exhibit an improvement in the MOR of the bending test. Some values, like compression strength parallel in wood treated with rosin or copper sulphate alone decreased slightly compared with the untreated control sample. This results are in agreement with those reported by Yildiz et al [21] and Winandy [22]. However, the compression strength parallel of wood treated with rosin-copper solution increased by $15 \%$ compared with the untreated control samples. This could ne attributed to the rosin reacting with copper ions to form an insoluble copper resinate compound [23].In our case this compound is in very small amount since the copper-chitosan chelate is more stable.

In our case we can observe in Table 7 an improvement in the MOR of the bending tests of impregnated wood. On the other hand, wood treated with the rosin-copper system showed a reduction in MOR 8\% and 9\% in MOE [24]. Su [25] found some reductions in MOR and MOE of poplar wood treated with some copper base preservatives.

In the simple extraction screws the density plays an important role. There is a slight improvement in the impregnated wood in terms of maximum load and stiffness in lateral extraction.

\section{CONCLUSIONS}

- TGA can see the wood pattern has a little higher temperature of decomposition in comparison of impregnated wood. This is due to that metals are added to the material, crystallinity is lost, or in other words, purity lost, which does not indicate that it does possess fireproof properties. The treatment generates an overlay via the salts that are added, achieving a lagging of ignition since you leave them not combust, which is reflected in the percentage of residual mass.

- Swelling and absorption are stressed that impregnated wood specimens are less dense and were drier, which absorbed more water. In the case of swelling, treated wood spread a little less while there is a significant difference with the pattern. 
- In static bending test, you could see clearly that there are no significant differences between treated and untreated. But if you see a trend for the modulus of rupture, which was higher, statistically speaking, showing the strength that brings the impregnation. As this adhered better to the surface faces of the specimens, when applying a load that stretch or compress up to break the external fibers, they presented greater resistance.

- Very similar with the compression testing parallel to the fiber, where the modulus of elasticity and the breaking strain do not have significant differences. But as in this case the densities are different, if divides the module and the tension for this parameter, you can see an improvement by the impregnation in the breaking strain. This is given to what is mentioning above, and further approved that the treatment hardens the wood.

- For the trial of wood fibers perpendicular compression, hardness test is clearly what has been mentioned, and is the rigidity of the material. This is shown since in both cases applied a load on the longitudinal sides of the specimens, where concentrated the largest number of impregnation. This pattern resulted in an improvement in the treated wood.

- Lateral extraction test, you can see that there are no differences between the woods for peak loads, with no screws. But if there is than impregnated wood turned out to have a better performance before movements and rigidity, obtaining a minor slip of screw. This is an advantage for the construction since it gives greater rigidity to the wooden structures, achieving a greater adhesion between plate and wood. Is worth noting that the failures that occurred in the trial was because of the OSB plate, rather than the screw or wood.

- Simple extraction test, parallel to the fiber direction, was given the case that impregnated wood obtained better data for each screw, however these improvements are not significant. The Drywall screw behaved better than the Turbo Screw, which may have response in that thread had larger, attaining a better adhesion on wood. Trials for the perpendicular direction, there is a significant difference between the screws, as is the case with side extraction test loads. This can be given to the drilling Guide made in the specimens, since it was almost of the Turbo screw thread's diameter. This resulted in a decrease in the contact surface, leaving screw to work only in the area of the wood that there was no drilling.

- As a recommendation, impregnated wood can be used in the world of construction since it has similar or better features that traditional wood. It can be used as floor slabs in constructions of partitions, it has properties anti fungi in addition to a better rigidity in the perpendicular compression. Another advantage is that not stained wood as CCA, which can varnish smoothly, keeping the beauty of natural wood. The stiffening of the joints can prevent the cracking of wooden structures, given that remain more attached to pieces of wood with structural panels.

\section{AUTHOR CONTRIBUTIONS}

All authors contributed equally to this work. All authors participated in the preparation of the research from the beginning to the end, such as establishing the research design, method and analysis. All authors discussed and finalized the analysis results to prepare the manuscript in accordance with the research progress.

\section{ACKNOWLEDGEMENTS}

The authors would like to thank the financial aid of ING 2030 I+D-1745.

\section{REFERENCES}

1. Ramage MH, Burridge H, Busse-Wicher M, Fereday G, Reynolds T, Shah DU, Wu G, Yu L, Fleming P, Densley-Tingley D, Allwood J, Dupree P, Linden PF and Sherman O. The wood from the trees: The use of timber in construction. Renew Sust Energ Rev 2017; 68: 33-359. https://doi.org/10.1016/j.rser.2016.09.107.

2. CORMA. Chile debe ser referente de construcción en madera [www Document]. URL http://www.corma.cl/corma-al-dia/nacional/Chile-debeser-referente-de-construcción-en-madera- (2016, accessed 11 October 2016).

3. CORMA, recursos renovables. Plantaciones forestales y bosques naturales. Preguntas frecuentes. [www Document]. URL http:// www.senado.cl , appsenado (accessed 11 October 2016).
4. INFOR. Estadísticas Forestales [www Document]. Inst. For. Chile, INFOR. URL https://wef.infor.cl/bannerdestacados/2018/031/destacado_31.php (2018, accessed 17 May 2018).

5. Asdrubali F, Ferracuti B, Lombardi L, Guattari C, Evangelisti L and Grazieschi G. "A review of structural, thermo-physical, acoustical, and environmental properties of wooden materials for building applications". Build Environ 2017; 114: $307 \quad-\quad 332$ http://dx.doi.org/10.1016/j.buildenv.2016.12.033.

6. Rodríguez $\mathrm{C}$ and Vergara E. Propiedades físicas y mecánicas de la madera de pinus canariensis crecido en el secano de la Región del Maule, Chile. Bosque 2008; 29 (3):192-196.

7. Suirezs TM. "Efecto de la impregnación con CCA (cromo-cobre- arsénico) sobre las propiedades físicas y mecánicas de la madera de pinus Taeda L. implantado en la Provincia de Misiones". Tesis de maestría, Universidad Nacional de Misiones, Facultad de Ciencias Forestales, Argentina, 2000.

8. Montero DI. "Resistencia a la flexión estática de madera de pinus radiata D.Don impregnada con Cobre Alcalino Cuaternario (ACQ-D)". Tesis de pregrado, Universidad de Chile, Facultad de Ciencias Forestales y conservación de la naturaleza, Chile, 2010.

9. De Souza Almeida A, Criscuolo G, Hendrigo de Ameida T, Christoforo A, Chahund E, Branco L, Pinheiro R and Rocco F. Influence of CCA-A Preservative on Physical-Mechanical Properties of Brazilian Tropical Woods. Bioresourses 2019; 14 (2): 3030-3041.

10. ASTM D1761:2012. American Society for Testing and Material. Standard Test Methods for Mechanical Fasteners in Woods.

11. Luna JN, Bejarano JO and González JM. Esfuerzo de extracción de clavos y tornillos para madera en cuatro especies de pino de Durango, México. Investigación y ciencia de la Universidad Autónoma de Aguascalientes 2014; Número 61: 41 - 47.

12. NCh 1198:2014. "Madera - Construcciones en madera - Cálculo".

13. NCh 987:1986. "Madera - Determinación de las propiedades mecánicas Ensayo de flexión estática".

14. NCh 176/2:1988. "Madera - Parte 2: Determinación de la Densidad"

15. NCh 176/1:1984. "Madera - Parte 1: Determinación de la Humedad".

16. UNE-EN 317:1994. "Tableros de partículas y tableros de 583 fibras. Determinación de la hinchazón en espesor después de inmersión en agua. AENOR, 584, Madrid, España. URL.

17. NCh 973:1986. "Madera - Determinación de las propiedades mecánicas Ensayo de compresión paralelas".

18. NCh 974:1986. "Madera - Determinación de las propiedades mecánicas Ensayo de compresión perpendicular a las fibras".

19. NCh 978:1986. "Madera - Determinación de las propiedades mecánicas Ensayo de dureza".

20. Cárdenas-Triviño G and Cruzat-Contreras C. Study of aggregation of Gold Nanoparticles in Chitosan. J Clust Sci 2008; 29: 1081-1088, https://doi.org/10.1007/s10876-018-1419-x

21. GB/T 1941:2009. Wood- determination of static hardness, China.

22. Winandy JE. Effect of waterborne preservative treatment on mechanical properties: a review. Woodstock (MD) AWPA, In: Proceedings 1995; vol.91: 17-33.

23. Pizzi, A. A new approach to nontoxic, wide-spectrum, ground-contact wood preservatives. Part 1. Approach and reaction mechanism. Holsforchm 1993; 47 (3): 253-260.

24. Yildiz UC, Temiz A, Gezer ED and Yildiz S. Effects of wood preservatives on mechanical properties of yellow pine (pinus sylvestris L) wood. Build Environ 2004; 39: 1071

25. Su W. Functional synthesis of tree extractives and the application of wood preservation. PhD. Thesis. Northeast Forestry University, Harbin, China, 2008. 